\title{
Influence of the Admission Pattern on the Outcome of Patients Admitted to a Respiratory Intensive Care Unit: Does a Step-Down Admission Differ From a Step-Up One?
}

\author{
Ilaria Valentini MD, Angela Maria Grazia Pacilli MD, Paolo Carbonara MD, \\ Luca Fasano MD, Rita Vitale MD, Corrado Zenesini SS MD, \\ Rita Maria Melotti MD, Stefano Faenza MD, and Stefano Nava MD
}

\begin{abstract}
BACKGROUND: The outcomes of patients admitted to a respiratory ICU (RICU) have been evaluated in the past, but no study has considered the influence of location prior to RICU admission. METHODS: We analyzed prospectively collected data from 326 consecutive patients admitted to a 7-bed RICU. The primary end points were survival and severity of morbidity-related complications, evaluated according to the patient's location prior to RICU admission. Three admission pathways were considered: step-down for patients transferred from the ICUs of our hospital; step-up for patients coming from our respiratory wards or other medical wards; and directly for patients coming from the emergency department. The secondary end point was the potential influence of several risk factors for morbidity and mortality. RESULTS: Of the 326 subjects, $92(28 \%)$ died. Overall, subjects admitted in a step-up process had a significantly higher mortality $(P<.001)$ than subjects in the other groups. The mortality rate was $64 \%$ for subjects admitted from respiratory ward, $43 \%$ for those from medical wards, and $18 \%$ for subjects from both ICU and emergency department (respiratory ward vs medical ward $P=.04$, respiratory ward vs emergency department $P<.001$, respiratory ward vs ICU $P<.001$, medical ward vs emergency department $P<.001$, and medical ward vs ICU $P<.001)$. Subjects admitted from a respiratory ward had a lower albumin level, and Simplified Acute Physiology Score II was significantly higher in subjects following a step-up admission. About $30 \%$ of the subjects admitted from a respiratory ward received noninvasive ventilation as a "ceiling treatment." The highest odds ratios related to survival were subject location prior to RICU admission and female sex. Lack of use of noninvasive ventilation, younger age, female sex, higher albumin level, lower Simplified Acute Physiology Score II, higher Barthel score, and absence of chronic heart failure were also statistically associated with a lower risk of death. CONCLUSIONS: The pathway of admission to a RICU is a determinant of outcome. Patients following a step-up pattern are more likely to die. Other major determinants of survival are age, nutritional status and female sex. Key words: respiratory ICU; critically ill patient; noninvasive ventilation; weaning; ICU; acute respiratory failure. [Respir Care 2013;58(12):2053-2060. (C) 2013 Daedalus Enterprises]
\end{abstract}

\section{Introduction}

Respiratory ICUs (RICUs) have developed around the world as specialized single organ units providing an inter-

Drs Valentini, Pacilli, Carbonara, Vitale, and Nava are affiliated with the Department of Specialist, Diagnostic and Experimental Medicine; and Drs Fasano and Nava are affiliated with Pneumologia e Terapia Intensiva Respiratoria, Azienda Opedaliera Universitaria Sant Orsola-Malpighi, Bologna, Italy. Drs Zenesini and Melotti are affiliated with the Depart- mediate level of care between that supplied in ICUs and in general wards. ${ }^{1}$ This model of care has been generally

\footnotetext{
ment of Public Health, Epidemiological Service, Local Health Authority of Bologna, and with Terapia Intensiva Polivalente, Azienda Opedaliera Universitaria Sant Orsola-Malpighi, Bologna, Italy. Dr Faenza is affiliated with Anestesiologia e Rianimazione, Azienda Opedaliera Universitaria Sant Orsola-Malpighi, Bologna, Italy.
}

The authors have disclosed no conflicts of interest. 
considered as an example of good management of hospital resources, enabling effective control of costs, ${ }^{2}$ although its actual cost-effectiveness has been questioned. ${ }^{3}$ According to the European Respiratory Society, a RICU is defined by the following characteristics: a nurse-patient ratio $>1: 3$, the presence of multifunctional monitors and life support ventilators, and the possibility of applying both invasive ventilation and noninvasive ventilation (NIV) in patients with lung failure or more than one organ failure. ${ }^{1}$ Depending on the patient's previous level of care, a RICU can provide: step-up care when admitting a patient transferred from a general ward, needing specific treatments, such as NIV or invasive ventilation and/or close monitoring, for an acute respiratory failure episode that developed during the hospital admission; or step-down care when a patient no longer requires all the facilities of an ICU but is not ready to be transferred to a general medical ward because of specific care needs (eg, management of tracheotomy) or still requires invasive ventilation. The third pathway of admission is from the emergency department. It is intuitive that patients who are getting better (ie, transferred from an ICU) may have more favorable outcomes than those who are getting worse (ie, those transferred from a medical ward), but this point has never been systematically investigated in the specific environment of the RICU, in which admissions occur from both directions (up and down), as opposed to an ICU, in which the admission flow is always from below (ie, only patients getting worse are admitted). Previous studies have addressed this issue in the ICU. For example, Gerber et al found that transfer of patients to a tertiary care ICU from the emergency department of a referring hospital was associated with significantly better outcomes than transfer from a referring hospital ICU, ${ }^{4}$ confirming the observations of other authors. ${ }^{5,6}$ It is unknown whether or not the patient's location prior to RICU admission influences in-hospital survival. An analysis of data on this issue could help clinicians and hospital administrators to better understand the role and effectiveness of the RICU. Surprisingly, none of the studies assessing patient characteristics and outcomes have considered these 3 admission patterns as variables potentially influencing outcomes. We therefore analyzed survival, patients' clinical characteristics at admission, and the variables that best correlated with patient outcome, in an RICU in a large academic hospital. We also analyzed the data with exclusion of patients who had do-not-intubate (DNI) orders.

\footnotetext{
Correspondence: Stefano Nava MD, Department of Specialist, Diagnostic and Experimental Medicine, Pneumologia e Terapia Intensiva Respiratoria, Azienda Opedaliera Universitaria Sant Orsola-Malpighi, Via Massarenti 9, 40138 Bologna, Italy. E-mail: stefano.nava@aosp.bo.it.
}

DOI: $10.4187 /$ respcare. 02225

\section{QUICK LOOK}

\section{Current knowledge}

Respiratory ICUs and intermediate care units care for patients who require mechanical ventilation but no longer require intensive care. These units improve weaning success and reduce costs.

\section{What this paper contributes to our knowledge}

The pathway of admission to a respiratory ICU is a major determinant of outcome. Patients transferred, because of clinical deterioration, from a medical or respiratory ward (step-up pattern) are more severely ill and have worse mortality than those transferred from an ICU (step-down pattern). Age, female sex, and nutritional status were major determinants of survival.

\section{Methods}

In an analysis of data prospectively collected and entered into a database, we evaluated 326 consecutive patients admitted over a 22-month period into our 7-bed RICU, with 3 beds located in a single room.

The study protocol was approved by the ethical and scientific committee of Azienda Opedaliera Universitaria Sant Orsola-Malpighi, Bologna, Italy. Subjects gave written consent to participation in the study: however, 34 subjects were not able to sign the consent form, and in these cases a relative signed on their behalf. In 18 of these cases the subject was later able to sign the consent form.

The primary end point of the study was the impact of the subject's location prior to RICU admission on survival and severity score. The 3 different pathways of admission were classified as follows:

- Step-down: admitted from one of the 3 ICUs in our hospital (general ICU, post-surgical ICU, and posttransplant/extracorporeal membrane oxygenation [ECMO] ICU)

- Step-up: admitted from a ward in our hospital (respiratory, internal medicine, gerontology, cardiology, physical therapy, orthopedic, or hematology)

- Directly: admitted from the emergency department

We recorded age, sex, admission comorbidities, admission albumin level, worst Simplified Acute Physiology Score II (SAPS II) measured within the first 24 hours of RICU admission, ${ }^{7}$ Barthel index, blood-gas values, longterm-oxygen or mechanical ventilation before hospitalization, invasive ventilation or NIV in the RICU, hospital stay before RICU admission, causes of acute respiratory 
failure (eg, exacerbation of COPD, heart failure, pneumonia, or ARDS), ${ }^{8}$ destination after discharge, and new prescription of invasive ventilation, NIV, or oxygen therapy at discharge. Subjects were considered to have previously diagnosed COPD if post-bronchodilator $\mathrm{FEV}_{1} / \mathrm{FVC}$ was $\leq$ 0.7.9 The diagnosis of hypoxemic respiratory failure was based on a $\mathrm{P}_{\mathrm{aO}} / \mathrm{F}_{\mathrm{IO}_{2}} \leq 300 \mathrm{~mm} \mathrm{Hg} .{ }^{10}$ The secondary end point was the potential influence of the abovementioned variables, except the destination at discharge and the new prescription of oxygen and/or ventilation, on survival, both according to the location prior to RICU admission and as a whole group.

\section{Statistical Analysis}

With regards to the 3 different patterns of admission to the RICU, for the data analysis we considered our respiratory ward as a stand-alone unit inside the step-up pathway, due to the fact that the RICU is located inside the respiratory ward and shares the same medical staff.

Results are expressed as mean \pm SD for continuous variables, and percentages for categorical variables. Demographic and disease characteristics were compared among the 4 provenances (respiratory ward, medical ward, emergency department, and ICU), using the Pearson chisquare test for categorical variables and one-way analysis of variance, followed by the Scheffé post hoc test for continuous variables.

We used univariate and multivariate logistic regression analyses to investigate mortality-related risk factors and to determine independent risk factors related to mortality. The following variables were entered into the univariate and multivariate analyses: age, sex, number of comorbidities, albumin level, worst SAPS II within the first 24 hours of RICU admission, Barthel Index, blood-gas values, longterm oxygen or ventilatory therapy before hospitalization, invasive ventilation or NIV on RICU admission, hospital stay before RICU admission, and causes of acute respiratory failure. The odds ratios were used to identify factors associated with survival. A $P$ value $<.05$ was considered statistically significant. Statistical analyses were conducted with statistics software (Stata/IC, StataCorp, College Station, Texas).

\section{Results}

\section{Primary Outcomes}

The Figure illustrates the flow of subjects admitted to our RICU during the study period, and their mortality rates. Ninety-two subjects (28\%) died. Overall, the step-up subjects (from a respiratory ward or medical ward) had significantly higher mortality $(P<.001)$ than the stepdown subjects (from an ICU) or the subjects from the

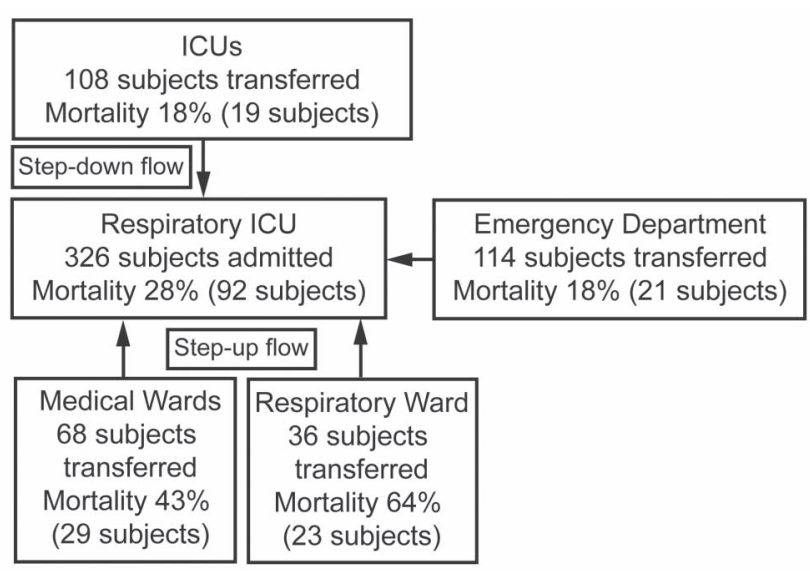

Figure. Admission to the respiratory ICU from other departments.

Table 1. Causes of Death

\begin{tabular}{lc}
\hline \hline & $\begin{array}{c}\text { Subjects } \\
\text { no. }(\%)\end{array}$ \\
\hline Severe sepsis or septic shock & $33(36)$ \\
Refractory respiratory acidosis & $9(10)$ \\
ARDS & $2(2)$ \\
Ischemic heart attack & $21(23)$ \\
Do-not-intubate order & $27(29)$ \\
End-stage idiopathic pulmonary fibrosis & $10(11)$ \\
End-stage cancer & $8(8)$ \\
End-stage COPD & $9(10)$ \\
\hline
\end{tabular}

emergency department. The statistical differences in mortality between the units were: $P=.04$ for respiratory ward versus medical ward, $P<.001$ for respiratory ward versus emergency department, $P<.001$ for respiratory ward versus ICU, $P<.001$ for medical ward versus emergency department, and $P<.001$ for medical ward versus ICU.

Sixty subjects were from the post-surgical ICU, 45 from the general ICU, and 3 from the post-transplant/ECMO ICU. There was no statistically significant difference in mortality rate between subjects from the post-surgical ICU $(11 / 60,18 \%)$ and the general ICU $(7 / 45,16 \%)$. The causes of death were mainly related to sepsis or end-stage pulmonary disease, in particular in subjects with a DNI order. Overall, of the 326 subjects, 27 with a DNI order died, accounting for $29 \%$ of the 92 subjects who died in the study. These 27 subjects comprised 8 with advanced cancer (8\% of all deaths), 10 with end-stage pulmonary fibrosis (11\% of all deaths), and 9 with end-stage COPD (10\% of all deaths), who had refused invasive treatments (Table 1).

The mortality rate in the 285 subjects without DNI order was similar to the overall mortality rate, with the same statistical difference between step-up and step-down admission $(P<.001)$. Of these 285 subjects, $51(18 \%)$ died: 
Table 2. Subject Characteristics on Admission to the Respiratory ICU, Based on the Subject's Previous Location

\begin{tabular}{|c|c|c|c|c|c|c|}
\hline & \multicolumn{4}{|c|}{ Subject's Previous Location } & \multirow{2}{*}{$\begin{array}{c}P \\
\text { Between } \\
\text { Groups }\end{array}$} & \multirow[b]{2}{*}{$P$ After Scheffé Post Hoc Test } \\
\hline & $\begin{array}{l}\text { Respiratory } \\
\text { Ward }\end{array}$ & $\begin{array}{l}\text { Medical } \\
\text { Ward }\end{array}$ & $\begin{array}{l}\text { Emergency } \\
\text { Department }\end{array}$ & ICU & & \\
\hline Age, y & $77.36 \pm 9.24$ & $70.46 \pm 17.55$ & $72.28 \pm 16.25$ & $69.16 \pm 15.87$ & .050 & $\begin{array}{l}.009 \text { for respiratory ward vs ICU } \\
.21 \text { for respiratory ward vs medical ward } \\
.42 \text { for respiratory ward vs emergency department } \\
.90 \text { for medical ward vs emergency department } \\
.96 \text { for medical ward vs ICU } \\
.54 \text { for emergency department vs ICU }\end{array}$ \\
\hline Male/female, no. & $25 / 11$ & $32 / 36$ & $52 / 62$ & $53 / 55$ & .09 & \\
\hline $\begin{array}{l}\text { Simplified Acute } \\
\text { Physiology Score II }\end{array}$ & $43.47 \pm 11.45$ & $38.34 \pm 15.91$ & $34.38 \pm 12$ & $32.83 \pm 12.65$ & $<.001$ & $\begin{array}{l}.30 \text { for respiratory ward vs medical ward } \\
.005 \text { for respiratory ward vs emergency department } \\
.001 \text { for respiratory ward vs ICU } \\
.27 \text { for medical ward vs emergency department } \\
.050 \text { for medical ward vs ICU } \\
.85 \text { for emergency department vs ICU }\end{array}$ \\
\hline Albumin, g/dL & $2.93 \pm 0.50$ & $3.22 \pm 0.49$ & $3.46 \pm 0.52$ & $3.23 \pm 0.52$ & $<.001$ & $\begin{array}{l}.06 \text { for respiratory ward vs medical ward } \\
.001 \text { for respiratory ward vs emergency } \\
\text { department } \\
.03 \text { for respiratory ward vs ICU } \\
.03 \text { for medical ward vs emergency department } \\
>.99 \text { for medical ward vs ICU } \\
.01 \text { for emergency department vs ICU }\end{array}$ \\
\hline Time prior to admission, $\mathrm{d}$ & $16.3 \pm 18.6$ & $14.8 \pm 19.81$ & $2.32 \pm 4.10$ & $14.9 \pm 18.16$ & $<.001$ & $\begin{array}{l}.97 \text { for respiratory ward vs medical ward } \\
<.001 \text { for respiratory ward vs emergency } \\
\text { department } \\
.97 \text { for respiratory ward vs ICUs } \\
<.001 \text { for medical ward vs emergency department } \\
>.99 \text { for medical ward vs ICU } \\
<.001 \text { for emergency department vs ICU }\end{array}$ \\
\hline $\begin{array}{l}\text { Age-adjusted Charlson } \\
\text { Comorbidity Index }\end{array}$ & $8.69 \pm 2.31$ & $6.49 \pm 1.89$ & $4.67 \pm 2.35$ & $5.51 \pm 2.19$ & .001 & $\begin{array}{l}<.01 \text { for respiratory ward vs emergency department } \\
<.02 \text { for respiratory ward vs ICU } \\
.06 \text { for respiratory ward vs medical ward } \\
.07 \text { for medical ward vs emergency department } \\
.34 \text { for medical ward vs ICU } \\
.27 \text { for emergency department vs ICU }\end{array}$ \\
\hline \multicolumn{7}{|l|}{ Causes of exacerbation, $\%$} \\
\hline COPD exacerbation & 64 & 61 & 73 & 54 & .04 & \\
\hline $\begin{array}{l}\text { Hypoxic respiratory } \\
\text { failure }\end{array}$ & 33 & 52 & 35 & 49 & .03 & \\
\hline Chronic heart failure & 58 & 52 & 53 & 49 & .80 & \\
\hline
\end{tabular}

$12 / 25(48 \%)$ from the respiratory ward, $21 / 60$ (35\%) from a medical ward, $8 / 101(8 \%)$ from the emergency department, and 10/99 (10\%) from an ICU.

The subjects' characteristics at admission to the RICU, based on their previous location, are presented in Table 2. Subjects admitted from the respiratory ward had a significantly lower serum albumin level than those from an ICU or the emergency department $(P=.03$ and $P=.001$, respectively). SAPS II was significantly higher in the step-up subjects (from a medical or respiratory ward) than in the step-down subjects $(P=.005$ for respiratory ward vs emergency department, $P=.001$ for respiratory ward vs ICU, and $P=.050$ for medical ward vs ICU), except for medical ward versus emergency department. Almost all the subjects had more than one comorbidity, as shown by the Charlson Comorbidity Index scores, ${ }^{11}$ which were significantly higher in subjects who came from the respiratory ward $(P<.01$ for respiratory ward vs emergency department, $P<.02$ for respiratory ward vs ICU). The causes of admission were sometimes multiple, with overlap between groups (eg, COPD exacerbation plus pneumonia or heart failure) and rather homogenously distributed, but with little difference according to the location prior to RICU admission. The time prior to RICU admis- 
Table 3. Ventilation Mode on Admission and at Discharge

\begin{tabular}{|c|c|c|c|c|}
\hline & \multicolumn{4}{|c|}{ Subjects, no. (\%) } \\
\hline & $\begin{array}{l}\text { Respiratory } \\
\text { Ward }\end{array}$ & $\begin{array}{l}\text { Medical } \\
\text { Ward }\end{array}$ & $\begin{array}{l}\text { Emergency } \\
\text { Department }\end{array}$ & ICU \\
\hline \multicolumn{5}{|l|}{ At RICU admission } \\
\hline Noninvasive ventilation & $9(9)$ & $20(20)$ & $52(51)$ & $20(20)$ \\
\hline $\begin{array}{l}\text { Noninvasive ventilation as ceiling } \\
\text { treatment (in do-not-intubate subjects) }\end{array}$ & $11(27)$ & $8(19)$ & $13(32)$ & $9(22)$ \\
\hline No ventilation & $12(14)$ & $20(24)$ & $28(34)$ & $23(28)$ \\
\hline Invasive ventilation & $4(11)$ & $20(20)$ & $21(19)$ & $56(50)$ \\
\hline \multicolumn{5}{|l|}{ At RICU discharge } \\
\hline Noninvasive ventilation & $16(21)$ & $18(23)$ & $29(38)$ & $14(18)$ \\
\hline Invasive ventilation & $2(4)$ & $18(35)$ & $8(15)$ & $\begin{array}{c}24(46) \\
20 \text { tracheotomies }\end{array}$ \\
\hline No ventilation & $18(9)$ & $33(17)$ & $76(39)$ & $70(35)$ \\
\hline
\end{tabular}

sion was statistically different between the groups, particularly between the subjects from the emergency department and those from the other locations.

As shown in Table 3, overall about $25 \%$ of the subjects did not require any form of ventilation. More than $50 \%$ of the subjects transferred from an ICU were invasively ventilated (either via an endotracheal tube or tracheotomy). About $30 \%$ of the subjects transferred from our respiratory ward received NIV as a "ceiling treatment." At discharge the majority of subjects did not need any ventilatory support. No statistical differences were found between the 4 groups in terms of ventilation method on admission. Less than $6 \%$ of the subjects were discharged home directly from the RICU; most of the subjects (62\%) were transferred from the RICU to our respiratory ward. Only $3 \%$ of the survivors needed re-admission to an ICU.

\section{Secondary Outcomes}

As shown in Table 4, the univariate analysis shows that the factor with the highest odds ratio related to survival was location prior to RICU admission. Subjects transferred from the emergency department or ICU had the highest chance of survival. Lack of NIV use, younger age, female sex, higher albumin level, lower SAPS II, higher Barthel score, longer hospital stay prior to RICU admission, and absence of chronic heart failure were statistically associated with a lower risk of death.

The multivariate analysis found that some of those variables lost their individual power. Considering categorical variables, the probability of survival was almost 6 times higher for women, whereas subjects admitted from the respiratory ward had about a 4 times lower probability of survival than those admitted from the emergency department. Considering the continuous variables, survival prob-
Table 4. Prognostic Indices for Survival

\begin{tabular}{lcc}
\hline \hline & & \\
& $\begin{array}{l}\text { Odds } \\
\text { Ratio }\end{array}$ & $P$ \\
\hline Univariate logistic regression & & \\
Age (per 1 year increase) & 0.96 & .001 \\
Female sex & 2.62 & .001 \\
Location before RICU admission & 7.32 & .001 \\
Noninvasive ventilation vs no & 0.51 & .041 \\
$\quad$ ventilation at admission & & .01 \\
Albumin (per 1 g/dL increase) & 3.80 & .001 \\
Simplified Acute Physiology Score II & 0.92 & .001 \\
$\quad$ (per 1 unit increase) & & .001 \\
Heart failure & 0.53 & .011 \\
Barthel index (per 1 unit increase) & 1.04 & \\
Days before RICU admission & 0.98 & \\
$\quad$ (per 1 day) & & .001 \\
Multivariate analysis & & .02 \\
Sex (F vs M) & & \\
Location before admission & & \\
Albumin (per 1 g/dL increase) & 3.76 & \\
\hline RICU = respiratory ICU & 3.89 & \\
\hline
\end{tabular}

ability decreased by $8 \%$ for every one point increment of SAPS II. In contrast, for every $1 \mathrm{~g}$ increase of albumin concentration, the survival probability was 3 times higher.

\section{Discussion}

In this study we have demonstrated for the first time that the patient's location prior to RICU admission profoundly influences outcomes, since the step-down subjects and those admitted from the emergency department had a better survival rate than the step-up subjects who had transited 


\section{Influence of the Admission PATtern on OUtCome in a Respiratory ICU}

through a medical ward or respiratory ward. These latter subjects were also, on average, more severely ill than those transferred from an ICU or the emergency department, most likely because their conditions worsened while being outside of a "protected" environment.

In Europe, a RICU located inside an acute care hospital should admit patients suffering from acute or acute-onchronic respiratory failure not immediately needing endotracheal intubation but requiring close monitoring, patients with single organ failure needing invasive ventilation, patients requiring NIV, and patients to be weaned from invasive mechanical ventilation. ${ }^{1}$ In North America most of the intermediate care units accept a variety of patients, not just patients in respiratory failure, ${ }^{12,13}$ so the results of this study may not be generalized, but may basically reflect a different international attitude.

These different conditions reflect different flows of patients once admitted to a general hospital. For example, in a survey conducted in 26 RICUs in Italy, Confalonieri et $\mathrm{al}^{14}$ found that almost half the patients $(47 \%)$ were admitted from emergency departments, $19 \%$ from other medical wards, $18 \%$ from ICUs, $13 \%$ from specialist respiratory wards, and $2 \%$ following surgery. This is perfectly in keeping with the data collected in our 7-bed RICU in a general hospital for about 1,400 patients and serving a population of 800,000 inhabitants.

Despite the fact that several investigations have assessed the outcomes of patients admitted to RICUs, ${ }^{12-14}$ none has considered the effect of the admission pattern, which may serve to deliver step-down or step-up care or to admit directly from the emergency department. ${ }^{15}$ The clinical outcome of patients requiring ICU admission (the stepdown pattern) has been described in the recent literature, especially for the subset of patients requiring prolonged mechanical ventilation and transferred to a RICU located inside a rehabilitation center or long-term acute care hospital, which is increasingly utilized after a critical illness, especially in North America. ${ }^{16,17}$ Data collected on more than 3,000 patients admitted to 5 Italian RICUs, mainly dedicated to weaning from mechanical ventilation, showed a mortality rate of about $15 \%,{ }^{18}$ which is in line with our results. Concerning a RICU located inside an acute care hospital, Bigatello et $\mathrm{al}^{19}$ suggested that a considerable number of patients were ready to come off mechanical ventilation at the time of RICU admission, implying that in the preceding ICU stay, discontinuing mechanical ventilation had not always been a priority, and explaining the quite low mortality rate even 1 year after hospital admission.

The data obtained in the present study $(\sim 18 \%$ mortality) are in line with those from previous studies, and the deaths were homogenously distributed among patients from the 3 different ICUs of provenance. No differences were observed between the 2 main different locations prior to
RICU admission. This is probably because the purpose of our RICU is to admit mainly "respiratory" patients, with single organ failure, so the characteristics of our transferred subjects were rather homogeneous. No subjects were admitted from the coronary care unit of our hospital, since this is organized in such a way that the staff take direct care of their patients, even when these need mechanical ventilation, or in the worst case they have a "preferential channel" with our post-transplant/ECMO ICU.

The mortality rate of the subjects from the emergency department was similar to that of the subjects from the ICUs. This may be explained by the these subjects' SAPS II, which was almost identical to that of the subjects from the ICUs, despite that the latter were mainly invasively ventilated, but in a phase of clinical stability. The subjects from the emergency department were "acutely" ill and undergoing an episode of acute respiratory failure. Interestingly, $\sim 50 \%$ of this group of subjects were ventilated noninvasively; one could, therefore, have expected a better hospital survival, especially if the subjects were treated within a protected environment. However, not all the subjects were affected by acute hypercapnic respiratory failure, in which NIV is associated with the best outcome; in fact, some of the subjects had "pure" hypoxic respiratory failure, such as ARDS, in which NIV is associated with a higher failure rate and mortality. ${ }^{20}$ Indeed, some subjects, mostly those who were very elderly and with several comorbidities, had DNI orders, so NIV was a ceiling treatment with a palliative aim to improve dyspnea. ${ }^{21}$ In our study, NIV was a ceiling treatment in $41(13 \%)$ of the total 326 subjects.

The most interesting finding of the present study is that the mortality rate in the step-up subjects (transferred to the RICU after having transited through a general or specific ward) was higher than in those admitted from other locations, with those coming from the respiratory ward having the higher risk of death.

The step-up subjects had higher SAPS II and were older, so it is not surprising that their mortality rate was also much higher than that of subjects with lower SAPS II transferred from an ICU or the emergency department. It may, therefore, be claimed that it is the severity of disease itself rather than the location that determines these patients' outcome.22-24 Unfortunately, given the lack of a standardized database in all the units, we were unable to detect a progressive deterioration of clinical condition during the hospital stay. Simchen et $\mathrm{al}^{25}$ demonstrated that about $2 \%$ of all patients admitted to the regular departments of an acute care hospital deteriorate during their hospital stay and reach the criteria of admission to a critical care environment. The majority of these patients (55\%) were not, however, transferred early to the ICU or similar environment, so their mortality was likely to increase. Simchen et al concluded that prompt admission to a critical 
care environment in patients deteriorating while in hospital wards should be imperative to maximize survival, but that this occurred in only a small proportion of patients. This suggests that we should look carefully at patients admitted to wards with respiratory disease, in case we are mis-triaging some patients to lower levels of care than they truly need.

Another problem is the fact that intensivists (ie, those working in ICUs) are usually involved as "first-line call" for patients admitted to a medical ward, and that, due to the paucity of ICU beds, they often deny transfer for old patients or those with several comorbidities, since the physician's perception of poor prognosis is associated with less aggressive or invasive care. The paucity of beds is a limiting factor for access to a general ICU, at least in most European countries. The decision to admit a patient to this setting has been reported to be influenced by the physician's perception of prognosis, which has been shown to be overly pessimistic, with the risk of barring access to ICU to patients who may have a chance of surviving. ${ }^{26}$ Other studies from different countries have confirmed the existence of this trend, indicating that intensivists are very selective in allowing transfer to the ICU.27,28 Specialized ICUs such as RICUs may provide an alternative for the referral of patients who develop severe respiratory failure in a regular medical ward, but RICUs are generally present only in large hospitals, and, even when available, ward physicians tend to consult first with the general intensivists.

RICUs usually care for older, chronically ill patients, so it is likely that the higher mortality in patients admitted from the wards may simply reflect the fact that some of these patients had end-stage diseases. This is a striking finding in the patients transferred from our respiratory ward; in $31 \%$ of these subjects NIV was a ceiling treatment. However, subjects with DNI orders were separated in the analysis from other patients undergoing NIV treatment; they were also evenly distributed across patients from the various different pre-RICU locations: $27 \%$ were from the respiratory ward, $19 \%$ from medical wards, $32 \%$ from the emergency department, and $22 \%$ from ICUs, so their inclusion in the analysis does not alter the finding that pre-RICU location affects prognosis.

The present study confirms most of the previous findings of other investigators in the same setting, for example, that albumin level and age are predictors of hospital mortality. Malnutrition associated with advanced lung disease has been termed the "pulmonary cachexia syndrome": it is associated with an accelerated decline in functional status and is recognized as an independent predictor of mortality in patients with lung diseases. ${ }^{22}$

In the univariate analysis the use of NIV was associated with an increased risk of mortality, which was a surprising finding since NIV improves survival, compared to stan- dard medical treatment, at least in patients with acute hypercapnic respiratory failure. ${ }^{29}$ It should, however, be noted, as previously stated, that NIV was used in the RICU in some cases (in patients with DNI orders) as a palliative tool. Moreover, NIV was also used in patients with hypoxic respiratory failure, including those with pneumonia. Both these circumstances affect the perceived success of NIV in this study. Indeed, it is our policy to treat all patients with a COPD exacerbation with respiratory failure and a $\mathrm{pH}>7.25$ in the respiratory ward. ${ }^{30}$

Only a small proportion of our patients were discharged to home from the RICU, in line with data reported by Bigatello et al, ${ }^{19}$ who reported that only $2 \%$ of their patients were discharged to home.

Interestingly, we also confirmed that RICU admission is associated with a quite high rate of weaning from mechanical ventilation, since the percentage of patients invasively ventilated at discharge decreased from $70 \%$ to $40 \%$.

The present study has some biases. The first and probably most important is that the data were collected in a single RICU in an acute care hospital, and the results, therefore, may not be extrapolated to other hospitals and geographic locations. Second, almost all the patients had been admitted for medical problems, while only 3 were post-surgery patients, and they are therefore representative of only one part of the population admitted to a critical care environment. Lastly, as previously stated, it was often difficult to collect a complete clinical history (in particular, previous lung function data), especially from patients transferred from a medical ward, since these patients were often in critical condition on RICU admission.

\section{Conclusions}

We have shown that the pathway of admission to a RICU is one of the major determinants of outcome. Step-up patients, transferred because of clinical deterioration, from a medical or respiratory ward are more severely ill and therefore more likely to die. Age, female sex, and nutritional status were also major determinants of survival. The use of NIV in the RICU is often not curative but only palliative.

\section{REFERENCES}

1. European Respiratory Task Force on Epidemiology of Respiratory Intermediate Care in Europe. Respiratory intermediate care units: a European survey. Eur Respir J 2002;20(5):1343-1350.

2. Elpern EH, Solver MR, Rosen RL, Bone RC. The non-invasive respiratory care unit: patterns of use and financial implications. Chest 1991;99(1):205-208.

3. Vincent JL, Buchardi H. Do we need intermediate care units? Intensive Care Med 1999;25(12):1345-1349.

4. Gerber DR, Schorr C, Ahmed I, Dellinger P, Parrillo J. Location of patients before transfer to a tertiary care intensive care unit: Impact on outcome. J Crit Care 2009;24(1):108-113.

5. Durairaj L, Will JG, Torner JC, Doebbeling BN. Prognostic factors for mortality following interhospital transfers to the medical inten- 
sive care unit of a tertiary referral center. Crit Care Med 2003;31(7): 1981-1986

6. Rosenberg AL, Hofer TP, Strachan C, Watts CM, Hayward RA. Accepting critically ill transfer patients: adverse effect on a referral center's outcome and benchmark measures. Ann Intern Med 2003; 138(11):882-890.

7. Breslow MJ, Badawi O. Severity scoring in the critically ill: part 1 -interpretation and accuracy of outcome prediction scoring system. Chest 2012;141(1):245-252.

8. The ARDS Definition Task Force. Acute respiratory distress syndrome. The Berlin definition. JAMA 2012;307(23):2526-2533.

9. Celli BR, MacNee W; ATS/ERS Task Force. Standards for the diagnosis and treatment of patients with COPD: a summary of the ATS/ERS position paper. Eur Respir J 2004;23(6):932-946.

10. Roussos C, Koutsoukou A. Respiratory failure. Eur Respir J 2003; 22(47):3-14.

11. Charlson ME, Pompei P, Ales KL, MacKenzie CR. A new method of classifying prognostic comorbidities in longitudinal studies: development and validation. J Chron Dis 1987;40(5):373-383.

12. Gracey DR, Naessens JM, Viggiano RW, Koenig GE, Silverstein MD, Koenig GE. Outcomes of patients admitted to a chronic ventilator dependent unit in an acute care hospital. Mayo Clin Proc 1992; 67(2):131-136.

13. Latriano B, McCauley P, Astiz ME, Greenbaum D, Rackow EC. Non ICU care in hemodynamically stable mechanically ventilated patients. Chest 1996;109(6):1591-1596.

14. Confalonieri M, Gorini M, Ambrosino N, Mollica C, Corrado A. Respiratory intensive care units in Italy: a national census and prospective cohort study. Thorax 2001;56(5):373-378.

15. Nava S, Confalonieri M, Rampulla C. Intermediate respiratory intensive care units in Europe: a European perspective. Thorax 1998; 53(9):798-802.

16. Unroe M, Kahn JM, Carson SS, Govert JA, Martinu T, Sathy SJ, et al. One-year trajectories of care and resources utilization for recipients of prolonged mechanical ventilation: a cohort study. Ann Intern Med 2010;153(3):167-175.

17. Hall WB, Wills LE, Medvedev S, Carson SS. The implications of long-term acute care hospital transfer practices for measures of inhospital mortality and length of stay. Am J Respir Crit Care Med 2012;185(1):53-57.

18. Polverino E, Nava S, Ferrer M, Ceriana P, Clini E, Spada E, et al. Patients' characterization, hospital course and clinical outcomes in five Italian respiratory intensive care units. Intensive Care Med 2010; 36(1):137-142

19. Bigatello LM, Stelfox HT, Berra L, Schmidt U, Gettings EM. Outcome of patients undergoing prolonged mechanical ventilation after critical illness. Crit Care Med 2007;35(11):2491-2497.

20. Demoule A, Girou E, Richard JC, Taillé S, Brochard L. Benefits and risks of success or failure of noninvasive ventilation. Intensive Care Med 2006;32(11):1756-1765.

21. Nava S, Sturani C, Harti S, Magni G, Ciontu M, Corrado A, Simonds A. End-of-life decision-making in respiratory intermediate care units: a European survey. Eur Respir J 2007;30(1):156-164.

22. O'Meara D, Mireles Cabodevila E, Frame F, Hummell AC, Hammel J, Dweik RA, Arroliga AC. Evaluation of delivery of enteral nutrition in critically ill patients receiving mechanical ventilation. Am J Crit Care 2008;17(1):53-61.

23. Bagshaw SM, Webb SA, Delaney A, George C, Pilcher D, Hart GK, Bellomo R. Very old patients admitted to intensive care in Australia and New Zealand: a multi-centre cohort analysis. Crit Care 2009; (2): $13: R 45$.

24. Moretti M, Cilione C, Tamperi A, Fracchia C, Marchioni A, Nava S. Incidence and causes of non-invasive mechanical ventilation failure after initial success. Thorax 2000;55(10):819-825.

25. Simchen E, Sprung CL, Galai N, Zitser-Gurevich Y, Bar-Lavi Y, Levy L, et al. Survival of critically ill patients hospitalized in and out of intensive care. Crit Care Med 2007;35(2):449-457.

26. Wildman MJ, Sanderson C, Groves J, Reeves BC, Ayres J, Harrison $\mathrm{D}$, et al. Implications of prognostic pessimism in patients with chronic obstructive pulmonary disease (COPD) or asthma admitted to intensive care in the UK within the COPD and asthma outcome study (CAOS): multicentre observational cohort study. BMJ 2007; 335(7630): 1132.

27. Wildman MJ, O’Dea J, Kosopoulou O, Tindall M, Walia S, Khan Z. Variation in intubation decisions for patients with chronic obstructive pulmonary disease in one critical care network. Q J Med 2003; 96(8):583-951.

28. Escher M, Perneger TV, Chevrolet JC. National questionnaire survey on what influences doctors' decisions about admission to intensive care. BMJ 2004;329(7463):425.

29. Nava S, Hill N. Non-invasive ventilation in acute respiratory failure. Lancet 2009;374(9685):250-259.

30. Carlucci A, Delmastro M, Rubini F, Fracchia C, Nava S. Changes in the practice of non-invasive ventilation in treating COPD patients over 8 years. Intensive Care Med 2003;29(3):419-425.

This article is approved for Continuing Respiratory Care Education credit. For information and to obtain your CRCE

(free to AARC members) visit www.rcjournal.com

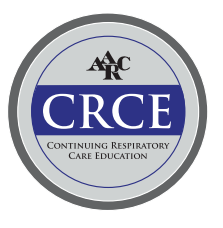

